\title{
Seismic Refraction Method: A Technique for Determining the Thickness of Stratified Substratum
}

\author{
Ochuko Anomohanran
}

Department of Physics, Faculty of Science, Delta State University, Abraka, Delta State, Nigeria

Received 2013-03-09, Revised 2013-05-14; Accepted 2013-07-17

\begin{abstract}
The seismic refraction survey is a very important geophysical technique used in the investigation of subsurface characteristics. This is why this study was carried out to emphasize the ability of the seismic refraction method in determining the thickness of stratified layers of soil and rock. The results obtained are generalized expressions that relate travel time, offset distance, velocity and thickness of subsurface layers.
\end{abstract}

Keywords: Seismic Refraction, Direct Arrivals, Geophones, Seismograph

\section{INTRODUCTION}

The seismic refraction method is one geophysical technique which is frequently used to determine the characteristics of soils and rocks (Ugwu, 2008; Ayolabi et al., 2009). Seismic refraction finds application in the determination of rock competence for engineering application, depth to bedrock, groundwater exploration, crustal structure and tectonics (Kilner et al., 2005; Asokhai et al., 2008; Varughese et al., 2011; Chiemeke and Aboh, 2012). The seismic refraction method is based on the measurement of the travel time of seismic waves refracted at the interfaces between subsurface layers of different velocity (Ayolabi et al., 2009).

The seismic signal is introduced into the subsurface via a shot point using explosives, hammer blow, dropped weight or an elastic wave generator (Igboekwe and Ohaegbuchu, 2011). The energy generated either travels directly through the upper layer (direct arrivals), or travel down through the various layers before returning to the surface (refracted arrivals). The energy is then detected on surface at a series of receivers called geophones spaced at regular intervals (Anomohanran, 2012). After a certain distance from the shot point, known as the cross over distance, the refracted signal is observed as a first arrival signal at the geophones (arriving before the direct arrival). Both compressional waves (P-waves) which provide depth information of interfaces and Shear waves (S-waves) which provide additional data about engineering properties of the subsurface media can be used in the seismic refraction method (Ayolabi et al., 2009; Igboekwe and Ohaegbuchu, 2011; Gabr et al., 2012).

In seismic refraction method, the signal from the shot returns to the surface by refraction at subsurface interfaces and is recorded at distances much greater than the depth of investigation (Igboekwe and Ohaegbuchu, 2011). The method relies on the tendency of acoustic velocities to increase with depth, which sometimes makes it insensitive to low velocity layers in the subsurface. Based on the analysis of the field data, the seismic surveyor draws a profile showing the thickness of the subsurface and a good idea of what materials they consist of (Ayolabi et al., 2009; Okiongbo et al., 2011; Igboekwe and Ohaegbuchu, 2011; Varughese et al., 2011; Gabr et al., 2012). Seismic refraction survey uses the process of critical refraction to infer interface depths and layer velocities. The data are usually presented as cross sectional plots representing P-wave path, velocities and depths to various interfaces.

The reason for this study is to present the field and data analysis procedure of the seismic refraction 
method and present its ability to determine the thickness of subsurface layers of the earth. This study will obtain the mathematical expression relating time of arrival of the waves, distance between source and geophones, velocity and depth of various layers.

\subsection{Mathematical Consideration}

The refraction survey gives rise to first arrival signals whose time are picked up from a seismogram and plotted as travel time curves (Igboekwe and Ohaegbuchu, 2011). The interpretation of the seismic signal is therefore set to determine the interface depths and layer velocities. This will be carried out in stages.

\subsection{Two Layered Subsurface}

Here we consider a two layer horizontal stratified substratum as shown in Fig. 1 where $\mathrm{x}$ is the offset distance from the energy source to the geophone. $Z_{1}$ is the thickness of the first layer, $V_{1}$ is the signal velocity in the first layer and $V_{2}$ is the signal velocity in the second layer. The path of the energy signal is defined as SABG (Fig. 1)

Using Fig. 1, we consider the wave SA which hits the layer boundary at the critical angle $\theta_{c}$. The total travel time for the refraction signal to travel from the source ' $\mathrm{S}$ ' to the geophone ' $G$ ' is expressed as Equation 1:

$\mathrm{T}_{\mathrm{SG}}=\mathrm{T}_{\mathrm{SA}}+\mathrm{T}_{\mathrm{AB}}+\mathrm{T}_{\mathrm{BG}}$

Which can also be expressed as Equation 2:

$$
\mathrm{T}_{\mathrm{SG}}=\frac{\mathrm{SA}}{\mathrm{v}_{1}}+\frac{\mathrm{AB}}{\mathrm{v}_{2}}+\frac{\mathrm{BG}}{\mathrm{v}_{1}}
$$

From Fig. 1, we deduce that $S A=B G=\frac{z_{1}}{\cos \theta c}$ and

$\mathrm{AB}=\mathrm{x}=2 \mathrm{Z}_{1} \tan \theta_{\mathrm{c}}$

Hence we write that Equation 3 and 4:

$$
\begin{aligned}
& \mathrm{T}_{\mathrm{SG}}=\frac{\mathrm{z}_{1}}{\mathrm{v}_{1} \cos \theta_{\mathrm{c}}}+\frac{\mathrm{x}-2 \mathrm{Z}_{1} \tan \theta_{\mathrm{c}}}{\mathrm{v}_{2}}+\frac{\mathrm{z}_{1}}{\mathrm{v}_{1} \cos \theta_{\mathrm{c}}} \\
& \mathrm{T}_{\mathrm{SG}}=\frac{\mathrm{z}_{1}}{\mathrm{v}_{1} \cos \theta_{\mathrm{c}}}+\frac{\mathrm{x}}{\mathrm{v}_{2}}-\frac{2 \mathrm{Z}_{1} \tan \theta_{\mathrm{c}}}{\mathrm{v}_{2}}
\end{aligned}
$$

This can be re-arranged to give:

$$
\mathrm{T}_{\mathrm{SG}}=\frac{\mathrm{x}}{\mathrm{v}_{2}}+\frac{2 \mathrm{Z}_{1}}{\mathrm{v}_{1} \cos \theta_{\mathrm{c}}}-\frac{2 \mathrm{Z}_{1} \sin \theta_{\mathrm{c}}}{\mathrm{v}_{2} \cos \theta_{\mathrm{c}}}
$$

Equation 7 represents the time taken by the wave to travel to the bedrock and back to the geophone. The time distance curve produces two segments with different slopes as shown in Fig. 2.

The travel time curves as shown in Fig. 2 is used to determine the velocities of the two layers. From Fig. 2, the slope of the first part gives $1 / v_{1}$ and the slope of the second part gives $1 / \mathrm{v}_{2}$. The inverse of slopes gives us the velocities of the subsurface (Igboekwe and Ohaegbuchu, 2011). The critical distance $\left(x_{c}\right)$ is the point on the surface at which the direct wave and the head wave arrived simultaneously. Before the critical distance, the direct waves arrive first while beyond the critical distance, the head wave arrives first. According to Fig. 2, $t_{1}$ is the intercept of the second segment of the straight line graph.

With all the necessary information obtained from the plot, the depth of the first layer is obtained to be Equation 8:

$$
\mathrm{Z}=\frac{\mathrm{t}_{1} \mathrm{v}_{1} \mathrm{v}_{2}}{2 \sqrt{\mathrm{v}_{2}^{2}-\mathrm{v}_{1}^{2}}}
$$

\subsection{Three Layered Subsurface}

The case of a three layered horizontal subsurface is as shown in Fig. 3. The interpretation of the three layered subsurface is based on the understanding that:

- The time signals are the direct arrivals in the first layer of thickness $Z_{1}$

- Critical refraction with angle $\theta_{2}$ takes place at top of the third layer

We shall again consider the wave which leaves the shot point $\mathrm{S}$ and travelled through the path $\mathrm{SA}, \mathrm{AB}, \mathrm{BC}$, $\mathrm{CD}$ and $\mathrm{DG}$. The total travel time from the source ' $\mathrm{S}$ ' to the geophone ' $\mathrm{G}$ ' is expressed as Equatin 9:

$\mathrm{T}_{\mathrm{SG}}=\mathrm{T}_{\mathrm{SA}}+\mathrm{T}_{\mathrm{AB}}+\mathrm{T}_{\mathrm{BC}}+\mathrm{T}_{\mathrm{CD}}+\mathrm{T}_{\mathrm{DG}}$ 


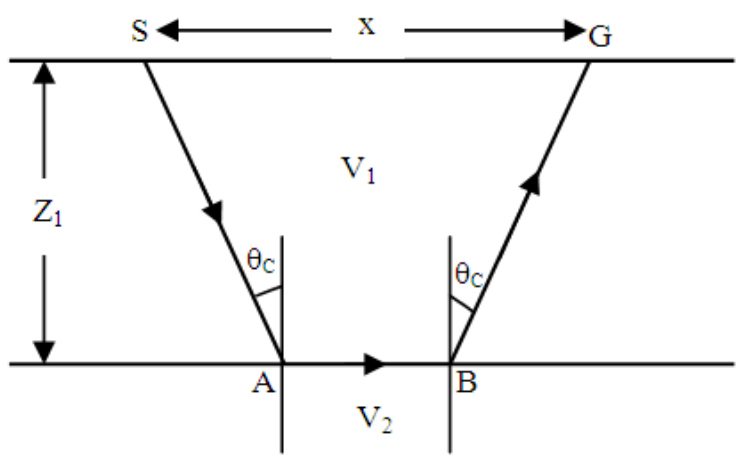

Fig. 1. A two layer horizontal stratified substratum

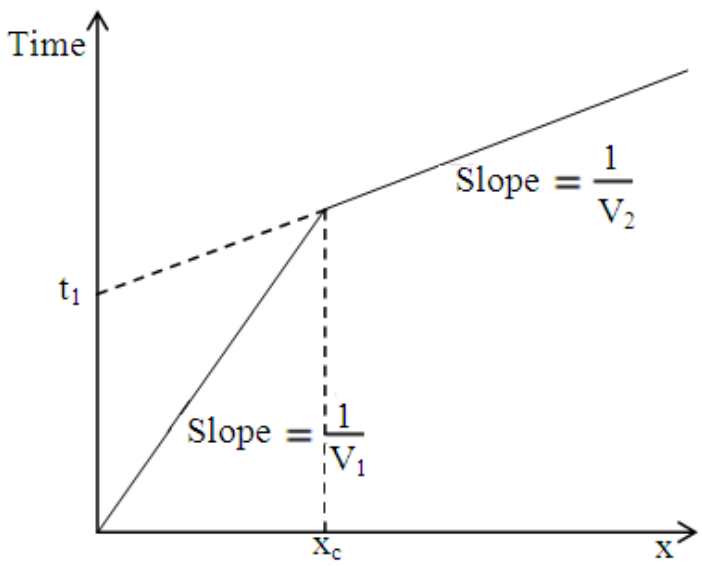

Fig. 2. Travel-Time graph for two layer surface

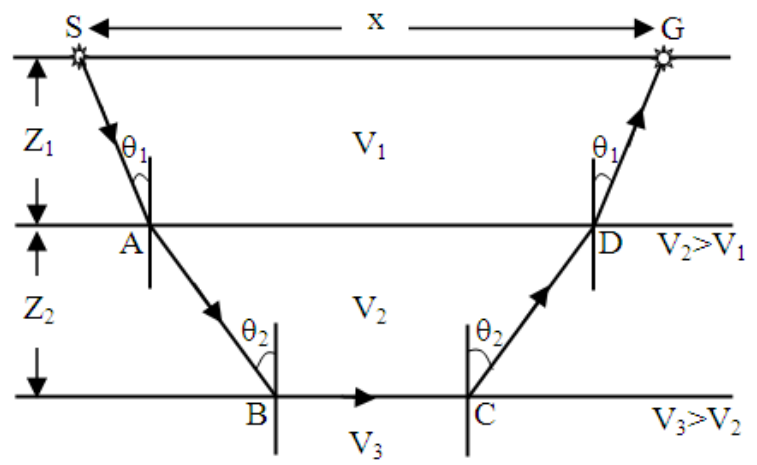

Fig. 3. A three layered horizontal stratified substratum

Which again is expressed as Equation 10:

$\mathrm{T}_{\mathrm{SG}}=\frac{\mathrm{SA}}{\mathrm{v}_{1}}+\frac{\mathrm{AB}}{\mathrm{v}_{2}}+\frac{\mathrm{BC}}{\mathrm{v}_{3}}+\frac{\mathrm{CD}}{\mathrm{v}_{2}}+\frac{\mathrm{DG}}{\mathrm{v}_{1}}$
Following from the fact that $\cos \theta_{1}=\frac{\mathrm{Z}_{1}}{\mathrm{SA}}$ and:

$$
\cos \theta_{2}=\frac{\mathrm{z}_{2}}{\mathrm{AB}}
$$

We can deduce that:

$$
\mathrm{T}_{\mathrm{SA}}=\mathrm{T}_{\mathrm{DG}}=\frac{\mathrm{z}_{1}}{\mathrm{v}_{1} \cos \theta_{1}}
$$

And:

$$
\mathrm{T}_{\mathrm{AB}}=\mathrm{T}_{\mathrm{CD}}=\frac{\mathrm{z}_{2}}{\mathrm{v}_{2} \cos \theta_{2}}
$$

Since $B C=X-2 Z_{1} \tan \theta_{1}-2 Z_{2} \tan \theta_{2}$ :

$$
\mathrm{T}_{\mathrm{BC}}=\frac{\mathrm{X}-2 \mathrm{z}_{1} \tan \theta_{1}-2 \mathrm{z}_{2} \tan \theta_{2}}{\mathrm{v}_{3}}
$$

Hence Equation 10 becomes Equation 11 and 12:

$$
\begin{aligned}
& \mathrm{T}_{\mathrm{SG}}=\frac{2 \mathrm{z}_{1}}{\mathrm{v}_{1} \cos \theta_{1}}+\frac{2 \mathrm{z}_{2}}{\mathrm{v}_{2} \cos \theta_{2}}+\frac{\mathrm{X}}{\mathrm{v}_{3}}-\frac{2 \mathrm{z}_{1} \sin \theta_{1}}{\mathrm{v}_{3} \cos \theta_{1}}-\frac{2 \mathrm{z}_{2} \sin \theta_{2}}{\mathrm{v}_{3} \cos \theta_{2}} \\
& =\frac{\mathrm{X}}{\mathrm{v}_{3}}+\frac{2 \mathrm{z}_{1}}{\cos \theta_{1}}\left[\frac{1}{\mathrm{v}_{1}}-\frac{\sin \theta_{1}}{\mathrm{v}_{3}}\right]+\frac{2 \mathrm{z}_{2}}{\cos \theta_{2}}\left[\frac{1}{\mathrm{v}_{2}}-\frac{\sin \theta_{2}}{\mathrm{v}_{3}}\right] \\
& =\frac{\mathrm{x}}{\mathrm{v}_{3}}+\frac{2 \mathrm{Z}_{1}}{\mathrm{v}_{1} \cos \theta_{1}}\left[1-\frac{\mathrm{v}_{1}}{\mathrm{v}_{3}} \sin \theta_{1}\right]+\frac{2 \mathrm{Z}_{2}}{\mathrm{v}_{2} \cos \theta_{2}}\left[1-\frac{\mathrm{v}_{2}}{\mathrm{v}_{3}} \theta_{2}\right]
\end{aligned}
$$

Since $\sin \theta_{1}=\frac{\mathrm{v}_{1}}{\mathrm{v}_{2}}, \sin \theta_{2}=\frac{\mathrm{v}_{2}}{\mathrm{v}_{3}}$ and $\operatorname{Sin}^{2} \theta+\operatorname{Cos}^{2} \theta=1$ Equation 13 becomes:

$\mathrm{T}_{\mathrm{SG}}=\frac{\mathrm{x}}{\mathrm{v}_{3}}+\frac{2 \mathrm{z}_{1} \cos \theta_{1}}{\mathrm{v}_{1}}+\frac{2 \mathrm{z}_{2} \cos \theta_{2}}{\mathrm{v}_{2}}$

The plot of the travel time against the offset distance gives a straight line graph with three segments as shown in Fig. 4.

The time intercepts $t_{1}$ and $t_{2}$ as shown in Fig. 4 can be obtained and used to determine the thickness of the different layers of soil or rock.

Using Equation 14, the time $t_{1}$ and $t_{2}$ are expressed as:

$$
\mathrm{t}_{1}=\frac{2 \mathrm{z}_{1} \cos \theta_{1}}{\mathrm{v}_{1}}
$$




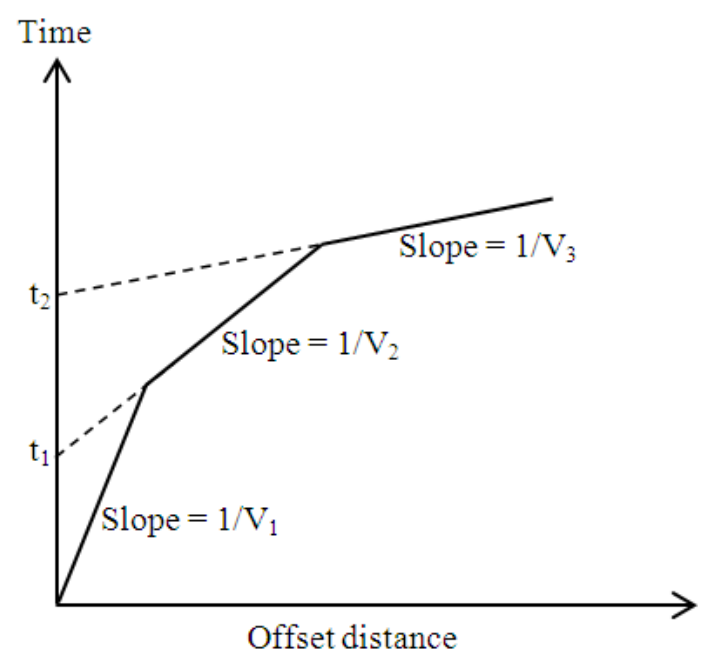

Fig. 4. Travel-time graph for three layered subsurface

And:

$$
\mathrm{t}_{2}=\frac{2 \mathrm{z}_{2} \cos \theta_{2}}{\mathrm{v}_{2}}
$$

Which transforms to give Equation 15 and 16 respectively:

$\mathrm{t}_{1}=\frac{2 \mathrm{z}_{1}\left(\mathrm{v}_{2}^{2}-\mathrm{v}_{1}^{2}\right)^{1 / 2}}{\mathrm{v}_{1} \mathrm{v}_{2}}$

And:

$\mathrm{t}_{2}=\frac{2 \mathrm{z}_{2}\left(\mathrm{v}_{3}^{2}-\mathrm{v}_{2}^{2}\right)^{1 / 2}}{\mathrm{v}_{2} \mathrm{v}_{3}}$

Using Equation 15 and 16, the thickness of the different layers are determined as Equation 17 and 18:

$$
\begin{aligned}
& \mathrm{Z}_{1}=\frac{\mathrm{t}_{1} \mathrm{v}_{1} \mathrm{v}_{2}}{2\left(\mathrm{v}_{2}^{2}-\mathrm{v}_{1}^{2}\right)^{1 / 2}} \\
& \mathrm{Z}_{2}=\frac{\mathrm{t}_{2} \mathrm{v}_{2} \mathrm{v}_{3}}{2\left(\mathrm{v}_{3}^{2}-\mathrm{v}_{2}^{2}\right)^{1 / 2}}
\end{aligned}
$$

\subsection{Four Layered Subsurface}

The case of a four layered horizontal surface is as shown in Fig. 5.

The interpretation of the four layered subsurface is based on the understanding that:
- The time signals are the direct arrivals in the first layer of thickness $Z_{1}$

- Critical refraction with angle $\theta_{3}$ also takes place at top of the fourth layer

We shall again consider the wave which leaves the shot point $\mathrm{S}$ and travelled through the path $\mathrm{SA}, \mathrm{AB}$, $\mathrm{BC}, \mathrm{CD}, \mathrm{DE}, \mathrm{EF}$ and FG. The total travel time from the source ' $\mathrm{S}$ ' to the geophone ' $\mathrm{G}$ ' is expressed as Equation 19:

$\mathrm{T}_{\mathrm{SG}}=\mathrm{T}_{\mathrm{SA}}+\mathrm{T}_{\mathrm{AB}}+\mathrm{T}_{\mathrm{BC}}+\mathrm{T}_{\mathrm{CD}}+\mathrm{T}_{\mathrm{DE}}+\mathrm{T}_{\mathrm{EF}}+\mathrm{T}_{\mathrm{FG}}$

Which again is expressed as Equation 20:

$\mathrm{T}_{\mathrm{SG}}=\frac{\mathrm{SA}}{\mathrm{V}_{1}}+\frac{\mathrm{AB}}{\mathrm{V}_{2}}+\frac{\mathrm{BC}}{\mathrm{V}_{3}}+\frac{\mathrm{CD}}{\mathrm{V}_{4}}+\frac{\mathrm{DE}}{\mathrm{V}_{3}}+\frac{\mathrm{EF}}{\mathrm{V}_{2}}+\frac{\mathrm{FG}}{\mathrm{V}_{1}}$

Following the same steps as in the case of the three layers subsurface, we have Equation 21 to 23:

$$
\begin{aligned}
& \mathrm{T}_{\mathrm{SG}}=\frac{2 \mathrm{z}_{1}}{\mathrm{v}_{1} \cos \theta_{1}}+\frac{2 \mathrm{z}_{2}}{\mathrm{v}_{2} \cos \theta_{2}}+\frac{2 \mathrm{z}_{3}}{\mathrm{v}_{3} \cos \theta_{3}}+\frac{\mathrm{x}}{\mathrm{v}_{4}}- \\
& \frac{2 \mathrm{z}_{1} \sin \theta_{1}}{\mathrm{v}_{4} \cos \theta_{1}}-\frac{2 \mathrm{z}_{2} \sin \theta_{2}}{\mathrm{v}_{4} \cos \theta_{2}}-\frac{2 \mathrm{z}_{3} \sin \theta_{3}}{\mathrm{v}_{4} \cos \theta_{3}} \\
& =\frac{\mathrm{x}}{\mathrm{v}_{4}}+\frac{2 \mathrm{z}_{1}}{\cos \theta_{1}}\left[\frac{1}{\mathrm{v}_{1}}-\frac{\sin \theta_{1}}{\mathrm{v}_{4}}\right]+\frac{2 \mathrm{z}_{2}}{\cos \theta_{2}}\left[\frac{1}{\mathrm{v}_{2}}-\frac{\sin \theta_{2}}{\mathrm{v}_{4}}\right]+ \\
& \frac{2 \mathrm{z}_{3}}{\cos \theta_{3}}\left[\frac{1}{\mathrm{v}_{3}}-\frac{\sin \theta_{3}}{\mathrm{v}_{4}}\right]
\end{aligned}
$$

$=\frac{\mathrm{X}}{\mathrm{V}_{4}}+\frac{2 \mathrm{z}_{1}}{\mathrm{~V}_{1} \cos \theta_{1}}\left[1-\frac{\mathrm{V}_{1}}{\mathrm{~V}_{4}} \sin \theta_{1}\right]+\frac{2 \mathrm{z}_{2}}{\mathrm{~V}_{2} \cos \theta_{2}}$

$\left[1-\frac{\mathrm{v}_{2}}{\mathrm{v}_{4}} \sin \theta_{2}\right]+\frac{2 \mathrm{Z}_{3}}{\mathrm{v}_{3} \cos \theta_{3}}\left[1-\frac{\mathrm{v}_{3}}{\mathrm{v}_{4}} \sin \theta_{3}\right]$

Which reduces to Equation 24:

$\mathrm{T}_{\mathrm{SG}}=\frac{\mathrm{X}}{\mathrm{V}_{4}}+\frac{2 \mathrm{Z}_{1} \cos \theta_{1}}{\mathrm{~V}_{1}}+\frac{2 \mathrm{Z}_{2} \cos \theta_{2}}{\mathrm{~V}_{2}}+\frac{2 \mathrm{Z}_{3} \cos \theta_{3}}{\mathrm{~V}_{3}}$

The plot of the travel time against the offset distance gives a straight line graph with four segments as shown in Fig. 6. 


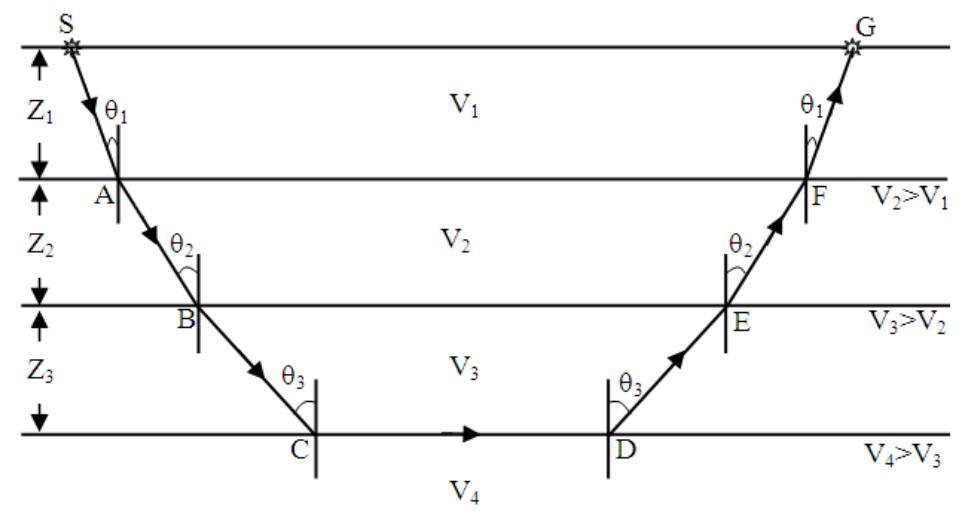

Fig. 5. A four layered horizontal stratified substratum

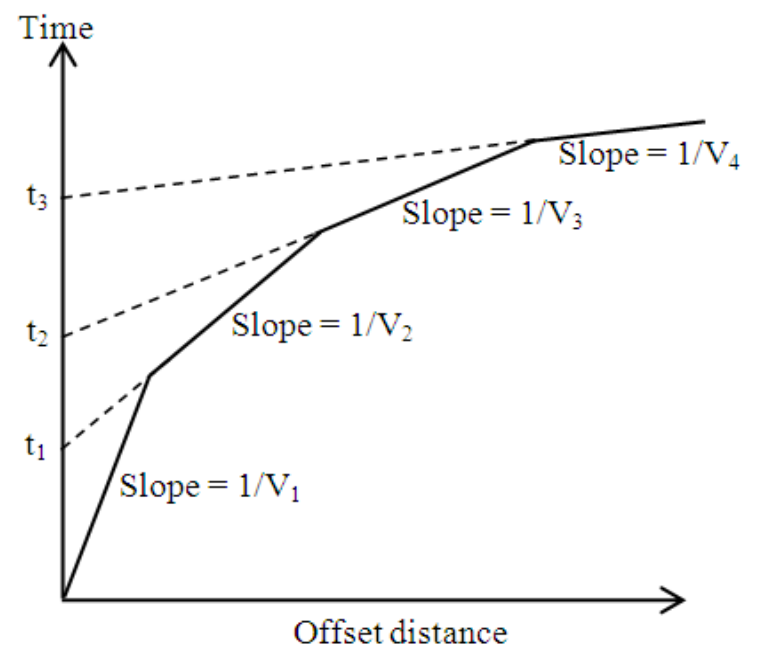

Fig. 6. Travel-Time graph for three layered subsurface

The time intercepts $t_{1}, t_{2}$ and $t_{3}$ are read from the plot and their values used to determine the thickness of the subsurface layers. The mathematical expressions are written as Equation 25 to 27:

$$
\begin{aligned}
& \mathrm{t}_{1}=\frac{2 \mathrm{z}_{1}\left(\mathrm{~V}_{2}^{2}-\mathrm{V}_{1}^{2}\right)^{1 / 2}}{\mathrm{~V}_{1} \mathrm{~V}_{2}} \\
& \mathrm{t}_{2}=\frac{2 \mathrm{z}_{2}\left(\mathrm{~V}_{3}^{2}-\mathrm{V}_{2}^{2}\right)^{1 / 2}}{\mathrm{~V}_{2} \mathrm{~V}_{3}} \\
& \mathrm{t}_{3}=\frac{2 \mathrm{z}_{3}\left(\mathrm{~V}_{4}^{2}-\mathrm{V}_{3}^{2}\right)^{1 / 2}}{\mathrm{~V}_{3} \mathrm{~V}_{4}}
\end{aligned}
$$

Hence the thickness of the subsurface becomes Equation 28 to 30 :

$$
\begin{aligned}
& Z_{1}=\frac{t_{1} V_{1} V_{2}}{2\left(v_{2}^{2}-v_{1}^{2}\right)^{1 / 2}} \\
& Z_{2}=\frac{t_{2} V_{2} V_{3}}{2\left(v_{3}^{2}-v_{2}^{2}\right)^{1 / 2}} \\
& Z_{3}=\frac{t_{3} V_{3} V_{4}}{2\left(v_{4}^{2}-v_{3}^{2}\right)^{1 / 2}}
\end{aligned}
$$

\subsection{Multi-Layered Subsurface}

The multi-layered subsurface is considered as a many plane horizontal layer as shown in Fig. 7.

The ray shown is refracted critically at the top of the $\mathrm{n}^{\text {th }}$ layer with speed $\mathrm{V}_{\mathrm{n}}$. Therefore, in determining the total travel time for a multi-layered subsurface, we consider the expressions in Equations 7,14 and 21 and generalize the interface travel time Equation 31 as:

$\mathrm{T}_{\mathrm{SG}}=\frac{\mathrm{X}}{\mathrm{V}_{\mathrm{n}}}+\sum_{\mathrm{i}=1}^{\mathrm{n}-1} \frac{2 \mathrm{Z}_{\mathrm{i}} \cos \theta_{\mathrm{i}}}{\mathrm{V}_{\mathrm{i}}}$

Where:

$\mathrm{n}=$ The number of layers,

$\theta_{\mathrm{i}}=$ The angle of incidence at the $\mathrm{i}^{\text {th }}$ interface

$\mathrm{Z}_{\mathrm{i}}=$ The depth at the base of a layer of velocity $\mathrm{V}_{\mathrm{i}}$

The generalized depth equation of the subsurface layers is also obtained after considering Equation 8, 17, 18, 28, 29 and 30 as Equation 32:

$$
Z_{i}=\frac{t_{i} V_{i} V_{i+1}}{2\left(V_{i+!}^{2}-V_{i}^{2}\right)^{1 / 2}}
$$




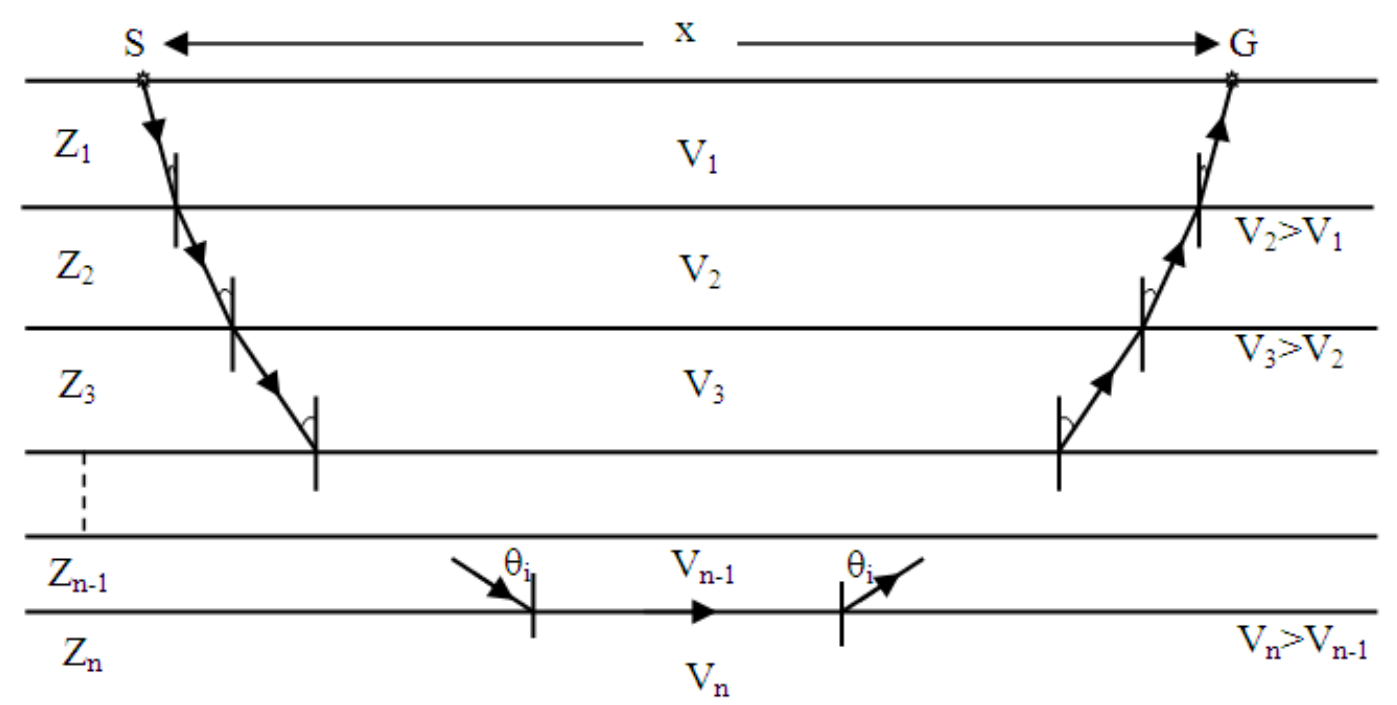

Fig. 7. A multi-layered horizontal stratified substratum

\section{CONCLUSION}

This study has highlighted the mathematical relations involved in determining the thickness of the various subsurface in a seismic refraction survey. A generalized equation for the determination of both the total travel time and thickness of the subsurface layers were obtained in this study. The results obtained are useful expressions of the physical parameters in the refraction interpretation.

\section{REFERENCES}

Anomohanran, O,, 2012. Geophysical interpretation of seismic reflection data obtained from Umureute and Amiynaibo area of Delta state. Nigeria, Nigerian J. Sci. Environ., 11: 148-153.

Asokhai, M.B., J.C. Egbai and E.C. Okolie, 2008. Using shallow reflection seismology for mapping bedrocks. Nigeria J. Sci. Environ., 7: 66-72.

Ayolabi, E.A., L. Adeoti, N.A. Oshinlaja, I.O. Adeosun and O.I. Idowu, 2009. Seismic refraction and resistivity studies of part of Igbogbo township, south-west Nigeria. J. Scient. Res. Dev., 11: 42-61.

Chiemeke, C.C. and H.O. Aboh, 2012. Delineation of aquiferous layers within the basement complex using joint inversion of seismic refraction tomography and high resolution 3D seismic reflection survey. Arch. Applied Sci. Res., 4: 400-405.
Gabr, A., A. Murad, H. Baker, K. Bloushi and H. Arman et al., 2012. The use of seismic refraction and electrical techniques to investigate groundwater aquifer, Wadi Al-ain, United Arab Emirates (UAE). Proceedings of the International Conference on Water Resources and Wetlands Sept. 14-16, Tulcea-Romania, pp: 94-99.

Igboekwe, M.U. and H.E. Ohaegbuchu, 2011. Investigation into the weathering layer using up-hole method of seismic refraction. J. Geol. Min. Res., 3: 73-86.

Kilner, M., L.J. West and T. Murray, 2005. Characterisation of glacial sediments using geophysical methods for groundwater source protection. J. Applied Geophys., 57: 293-305. DOI: 10.1016/j.jappgeo.2005.02.002

Okiongbo, K.S., E. Akpofure and E. Odubo, 2011. Determination of aquifer protective capacity and corrosivity of near surface materials in Yenagoa city, Nigeria. Res. J. Applied Sci., Eng. Tech., 3: 785-791.

Ugwu, S.A., 2008. Determination of depth to bedrock in Afikpo syncline of the Benue Trough, Nigeria, using seismic refraction methods. Scient. Afr.

Varughese, A., P. Kumar and N. Kumar, 2011. Seismic refraction survey a reliable tool for subsurface characterisation for hydropower projects. Proceedings of Indian Geotechnical Conference, Dec. 15-17, Kochi, pp: 137-139. 